\title{
The use of antibiotics in food technology: the case study of products from Moscow stores
}

\author{
Viktoriya Erofeeva ${ }^{1,2, *}$, Yulia Zakirova ${ }^{2}$, Sergey Yablochnikov ${ }^{1,3}$, Evgeny Prys $^{4}$, and Irina \\ Prys ${ }^{4}$ \\ ${ }^{1}$ Moscow Technical University of Communications and Informatics, 111024 Moscow, Russia \\ ${ }^{2}$ RUDN University, 117198 Moscow, Russia \\ ${ }^{3}$ Moscow State University of Food Production, 125080 Moscow, Russia \\ ${ }^{4}$ Academy of the FPS of Russia, 390000 Ryazan, Russia
}

\begin{abstract}
The global threat of the 21 st century is the uncontrolled use of antibiotics. Many bacteria have developed resistance to antibacterial drugs, resulting in drug-resistant superbugs. The article presents the results of the case study of Russian food products from the stores in the city of Moscow and analyzes them for the presence of antibiotics. The object of the study is the Russian market of animal products. The subject of the study is detecting the presence of antibiotics in food products on the Russian market. As a result of studying of the range of food products of animal origin, it has been revealed that the amount of harmful substances (such as antibiotics) meets the MPC standards, according to the Russian GOST standards. The research results obtained in laboratory conditions are of interest for assessing the prevalence of antibiotic residues in meat and dairy products. Based on the monitoring studies, it has been found out that most of the residual antibiotics were present in poultry meat. In all three samples, the antibiotic enrofloxacin was found but the MPC of the antibiotic was not exceeded (the norm is not more than $100 \mu \mathrm{g} / \mathrm{kg}$ ).
\end{abstract}

\section{Introduction}

The uncontrolled use of antibiotics has become a global threat of the 21 st century. Most bacteria have developed resistance to antibacterial drugs, resulting in drug-resistant superbugs. Animal products are the most important link in this chain being one of the basic components of a healthy diet. In the modern world, the struggle for a healthy lifestyle continues in the literal sense of this word. The effect of substances contained in food on a human body is being studied by scientists in different countries of the world. Modern scientific research methods make it possible to assess the health effects of various components of food. An increasing number of people understand that the diet, the consumed food have a major impact on human health and performance. Besides, due to publications on the significant effect of microbial resistance in animals on the treatment of infectious diseases in humans and medicine in general, the use of antibiotics in animal husbandry has become a crucial issue. The greatest danger in terms of prevalence and toxicity is posed by antibiotics because of their massive use in animal husbandry, poultry farms, beekeeping and in the process of industrial fish farming. Antibiotics are substances 
of microbial, animal or plant origin that can inhibit the growth of microorganisms or cause their death.

In the 21 st century, $70 \%$ of all manufacturers add antibiotics to healthy animals' feed to prevent, rather than cure, disease [1-4]. Antibiotics remain in meat, milk and eggs even after heat treatment and contribute to the development of allergies, gastrointestinal disorders in humans, as well as drug-resistant superbugs $[5,6]$. Along with resistance, the ineffectiveness of antibiotic therapy in the treatment of people, the latest generations of antibiotics included, is also increasing. Since 2004, scientists have not discovered any new group of antibiotics. Scientists believe that resistance to the groups of fluoroquinolones, macrolides, penicillins has been transmitted to people from animal husbandry, since the use of antibiotics by humans cannot be compared with their use in the agro-food industry to stimulate growth and prevent diseases: 1000 times more antibiotics are introduced into the body of animals and fish by weight, than used by humans [7-9]. The World Health Organization (WHO) and the World Bureau of Epizootics (OIE) have compiled a list of the most essential antibiotics used in veterinary medicine and medicine. A rational approach to the use of antibiotics in humans and animals is important for maintaining the effectiveness of the drug and its use in medicine. Maintaining animal health is critical to providing the population with safe food that meets the needs of a growing global population for more available animal protein in their diets. Overall, livestock accounts for $50 \%$ of all antibiotics produced in the world. On the one hand, during the life of an animal, the owner is interested in the use of antibiotics, since they can significantly increase the gain in live weight by increasing the use of nutrients in the diet, which in turn makes it possible to reduce feed costs and shorten the feeding period. On the other hand, interest in antimicrobial drugs in the production, storage and sale processes is due to the possibility of extending the shelf life of products. It also prevents premature death of animals. $70 \%$ of all manufacturers add antibiotics to healthy animals for the purpose of preventing, not treating, disease. It has also been found out that antibiotics remain in meat, milk and eggs even after being cooked. Antimicrobial drugs in meat and milk contribute to the development of allergies, gastrointestinal disorders in humans, as well as drug-resistant superbugs. The situation is aggravated by the fact that over the past 20 years, no new classes of antibiotics have been discovered, and the few developments that are underway at the moment will not be effective in the treatment of super-resistant strains [10-11].

The main type of milk used in the dairy industry is cow's. Antibiotics are used to treat inflammatory conditions, the most common of which is inflammation of the mammary glands (mastitis). Depending on the season, ten to eighty percent of dairy cows are susceptible to mastitis. When treating this disease, antimicrobial drugs are detected in milk. According to sanitary standards, milk from treated cows cannot be sold for three to fourteen days. Due to the lack of extended incoming control of incoming products, milk containing antibiotics is not disposed of, but mixed with milk from healthy animals. The content of antimicrobial drugs in milk decreases, but the residual amount of harmful substances continues to be detected. The Russian technical regulation for milk and dairy products, adopted in 2008, introduced a ban on the presence of antimicrobial drugs. However, in 2015 , the specifications changed, which led to changes in the availability of antibiotics, in components for baby food included.

The detection of antibiotics in raw milk is important for dairy processing plants. The presence of these substances in milk reduces the quality of the product.

In 2017 , there was a tendency towards a decrease in the production of feed antibiotics, which can be seen in Figure 1, however, the problem is still relevant, since in some of the studied samples of chicken meat, minced meat and milk in 2016-2019, residues of antimicrobial drugs were detected. 


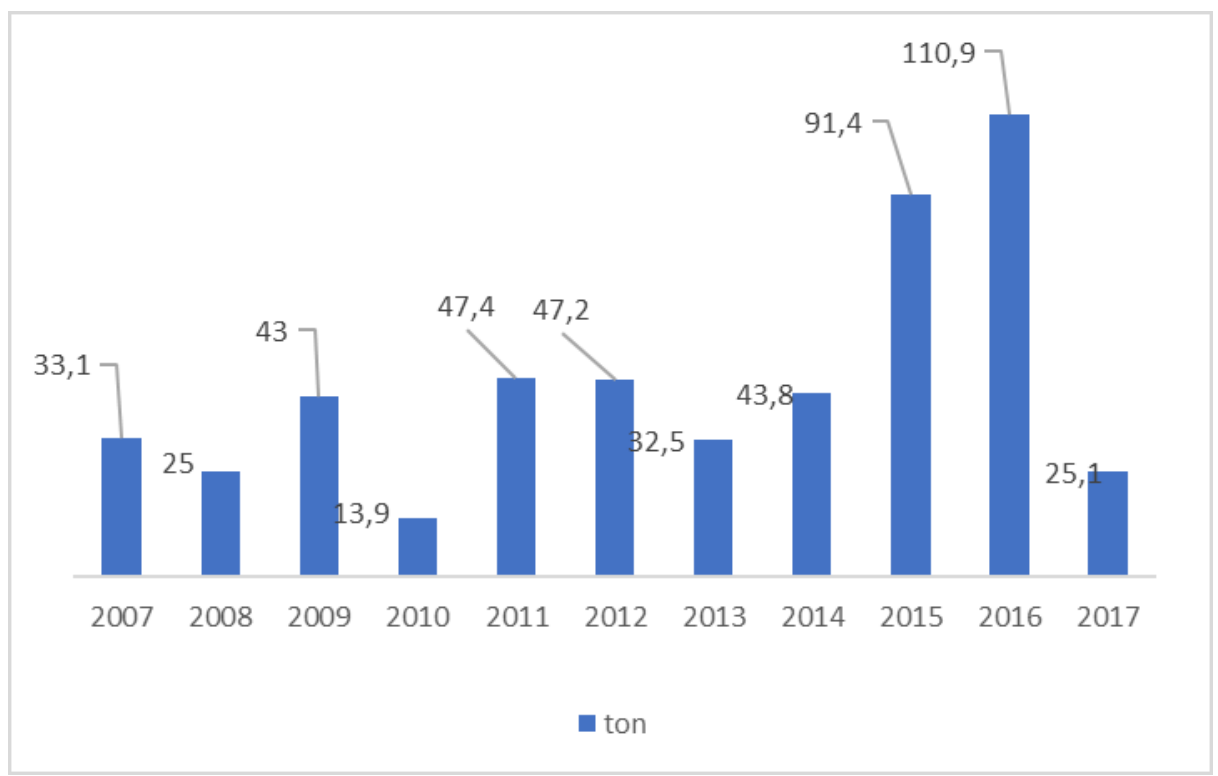

Fig. 1. Production of feed antibiotics in Russia in 2007-2017

The consequences of the irrational use of antibiotics in animal husbandry and their pollution with the remains of environmental objects (farm wastewater, food products, soil in places where manure was applied) resulted in a colossal acceleration of microbial variability, the formation of resistance and the emergence of superbugs that are resistant to most antimicrobial drugs. The problem is that since 2004, scientists have not discovered any new group of antibiotics (Figure 2).

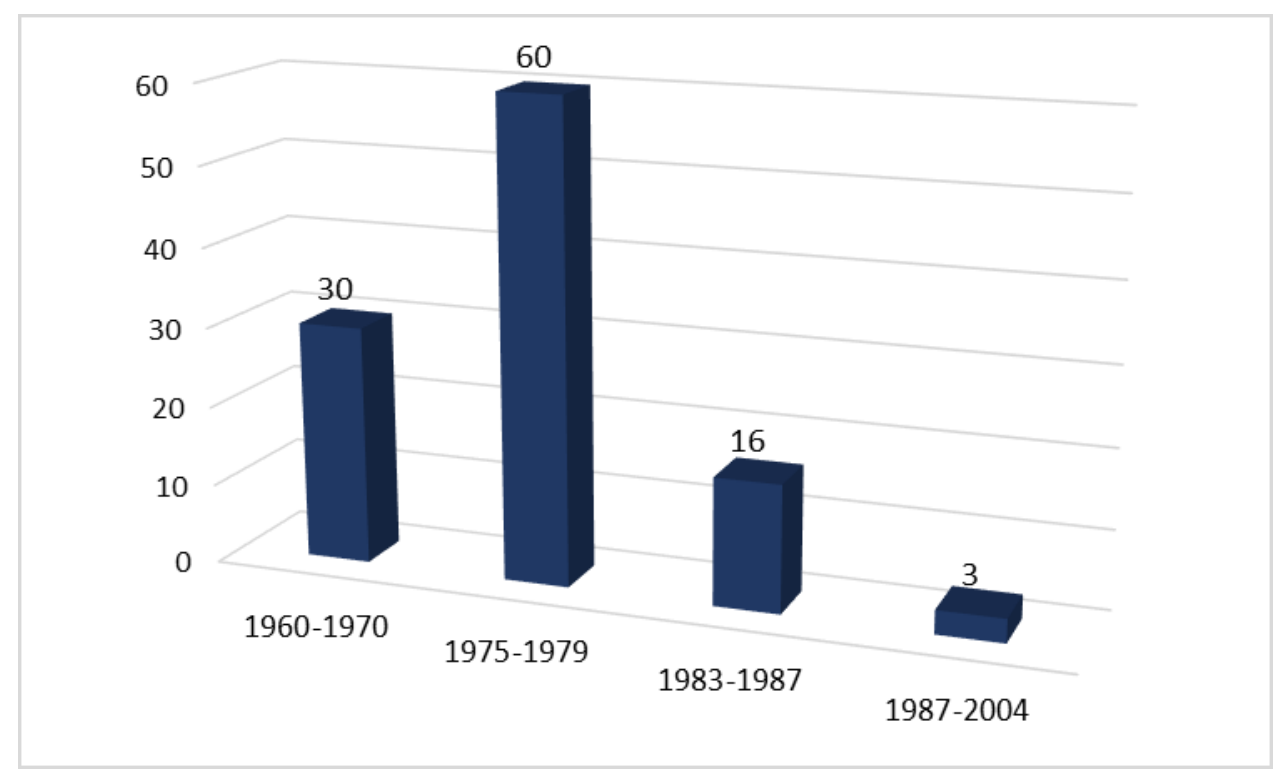

Fig. 2. Discovery of antibiotics 
Along with resistance, the ineffectiveness of antibiotic therapy in the treatment of people, including the latest generations of antibiotics, is also growing.

In 2019, a national program was developed in Russia to solve the problem of the use of antibiotics in animal husbandry. The program is aimed at introducing restrictions on the use of antimicrobial drugs, restricting their sales. In the long term, abandoning of the use of antibiotics in animal husbandry is supposed. The program also provides for the creation of a register of drugs prohibited and restricted for use in veterinary medicine. Responsibility for the use of antibiotics in livestock production lies primarily with the producers. However, even if there is a ban on the use of antibiotics, in order to increase the profitability of production, farmers will continue to use antimicrobial drugs, which cannot but satisfy pharmaceutical companies that are looking for new markets for antibiotics in countries with an insufficiently developed legal culture.

To date, the following serious problems of food contamination with antibiotics have emerged.

1. The increase in and spread of non-infectious human diseases associated with changes in the normal intestinal microflora: allergies, dysbiosis, atopy, obesity, irritable bowel syndrome;

2. When using organic fertilizers from animals that have been given antimicrobial drugs, the frequency of contamination with resistant bacteria of plants as well as the spread of micro doses of antibiotics increase and the chain reaction of resistance occurs.

3. Induction of horizontal transfer of resistance genes from foreign microorganisms to biotechnological microflora in its fermentation products.

4. The presence of multi-resistant strains in ready-to-eat dairy and meat products leads to their entry into the digestive tract in a live form, which is a serious health risk factor.

Despite the fact that since 2017 there has been a tendency towards a decrease in the production of feed antibiotics, the problem is still relevant, since in most of the samples studied - chicken meat, minced meat and milk (in 2018-2019) - residues of antimicrobial drugs were detected.

All of the above determines the relevance of this work.

The aim of our study is to determine the effect of antibiotics used in animal husbandry on human health. In accordance with this goal, in this work, we studied the range of food products and identified the amount and prevalence of harmful substances (for example, antibiotics) in milk, minced meat and poultry.

\section{Materials and methods}

The studies were carried out in 2018-2020 in the veterinary laboratory of the city of Serpukhov near Moscow. In order to determine the presence of antibacterial drugs in milk, Delvotest SP was used in accordance with MUK 4.1.3534-18. The material for the study was the store-bought milk of cattle of various manufacturers: "Sample No. 1" 3.2\% fat, purchased in the store "Auchan", "Sample No. 2" 3.2\% fat from the store "Perekrestok" and "Sample No. 3" 3.2\% fat, purchased in the hypermarket "Lenta".

To determine the residual amount of antibacterial drugs in minced meat, the "Antibiotest" was used to control meat and animal slaughter products for the presence of antibiotics and other antimicrobial chemotherapeutic substances in accordance with GOST $\mathrm{R}$ 55481-2013. The material for the study was minced meat from beef and pork of various manufacturers: homemade minced meat "Sample No. 1", bought in the store "Auchan", minced meat "Sample No. 2" from the store "Perekrestok" and chilled minced meat "Sample No. 3" purchased in the hypermarket "Lenta".

To determine the residual amount of antibacterial drugs in the carcasses of broiler chickens, the "Antibiotest" was used to control meat and animal slaughter products for the 
presence of antibiotics and other antimicrobial chemotherapeutic substances in accordance with GOST R 55481-2013.

The material for the study was the carcasses of broiler chickens from various manufacturers: a chicken carcass "Sample No. 1" purchased at the "Auchan" store, a chicken carcass "Sample No. 2" from the store "Perekrestok" and a chicken carcass "Sample No. 3" purchased in the hypermarket "Lenta".

\section{Results}

In accordance with the methodological guidelines MUK 4.1.3534-18, we analyzed the following product groups for the presence of antibiotics:

1) dairy products;

2) mixed mince (pork, beef);

3) poultry.

According to the results of the study of milk of the trade marks "Sample No. 1", "Sample No. 2" and "Sample No. 3", no antibiotics were found in the milk "Sample No. 1". The samples of milk "Sample No. 2" and "Sample No. 3" contained the antibiotic streptomycin, at a concentration of 0.01 per 1 liter of milk. This concentration of antibiotics in the studied milk samples is lower than the MPC value (Table 1).

Table 1. Detecting antibiotics in milk

\begin{tabular}{|c|c|c|}
\hline Product / Store & $\begin{array}{c}\text { Presence of antibiotics in } \\
\text { the product }\end{array}$ & $\begin{array}{c}\text { Exceeding of the } \\
\text { MPC (yes/no) }\end{array}$ \\
\hline $\begin{array}{c}\text { milk "Sample No. 1", 3.2\% / } \\
\text { "Auchan" }\end{array}$ & no \\
\hline $\begin{array}{c}\text { milk "Sample No. 2", 3.2\%/ } \\
\text { "Perekrestok" }\end{array}$ & streptomycin 0.01 \\
\hline $\begin{array}{c}\text { milk "Sample No. 3", 3.2\%/ } \\
\text { "Lenta" }\end{array}$ & streptomycin 0.01 & no \\
\hline
\end{tabular}

Thus, as the results of our research show, all milk samples are fit for consumption causing no harm to human health according to the permissible MPC values (Table 2).

Table 2. Permissible levels, $\mathrm{mg} / \mathrm{kg} / \mathrm{l}$, of antibiotics in milk and dairy products in accordance with TR CU 033/2013 "On the safety of milk and dairy products"

\begin{tabular}{|c|c|}
\hline Antibiotic groups & MPC, mg / l \\
\hline streptomycin & less than 0,2 \\
\hline tetracyclines & less than 0,01 \\
\hline penicillins & less than 0,004 \\
\hline chloramphenicol & less than 0,0003 \\
\hline
\end{tabular}

According to the results of the study of homemade minced meat of various brands, "no antibiotics were found in samples "No. 1"and "No. 2". The antibiotic sulfamethazine at a dose of $17.33 \mu \mathrm{g} / \mathrm{kg}$ was found in the minced meat of the manufacturer "Sample No. 3", bought in the hypermarket "Lenta", the concentration of which in the sample of minced meat does not exceed the MPC value. In the Russian Federation and the countries of the Customs Union, the content of sulfonamides in food is limited by the "Unified SanitaryEpidemiological and Hygienic Requirements for Goods Subject to Sanitary- 
Epidemiological Surveillance". According to this document, the total content of residues of all sulfanilamide preparations in meat, fat, liver and kidneys of all types of slaughtered animals and poultry should not exceed $0.1 \mathrm{mg} / \mathrm{kg}$. Our research has shown that samples of minced meat "Sample No. 1", "Sample No. 2" and "Sample No. 3" are fit for consumption inflicting no harm to human health (Table 3).

Table 3. Detecting antibiotics in minced meat

\begin{tabular}{|c|c|c|}
\hline Product/Store & $\begin{array}{c}\text { The presence of antibiotics in the } \\
\text { product } \boldsymbol{\mu g} / \mathbf{~ k g}\end{array}$ & $\begin{array}{c}\text { Exceeding of the MPC } \\
\text { (yes / no) }\end{array}$ \\
\hline $\begin{array}{c}\text { minced meat "Sample } \\
\text { No. 1" }\end{array}$ & not detected & no \\
\hline $\begin{array}{c}\text { minced meat "Sample } \\
\text { No. 2" }\end{array}$ & not detected & no \\
\hline $\begin{array}{c}\text { minced meat "Sample } \\
\text { No. 3" }\end{array}$ & sulfamethazine 17.33 & no \\
\hline
\end{tabular}

According to the results of the study of carcasses of broiler chickens "Sample No. 1", "Sample No. 2" and "Sample No. 3" the antibiotic enrofloxacin was detected in all three samples. In "Sample No. 1" the concentration of enrofloxacin was $3.72 \mu \mathrm{g} / \mathrm{kg}$, in "Sample No. 2" the concentration was $2.3 \mu \mathrm{g} / \mathrm{kg}$, in the carcass "Sample No. 3" the concentration of enrofloxacin was $8.31 \mu \mathrm{g} / \mathrm{kg}$ which is a high value (Table 4).

Table 4. Detecting antibiotics in poultry meat

\begin{tabular}{|c|c|c|}
\hline Product/Store & $\begin{array}{c}\text { The presence of antibiotics } \\
\text { in the product } \boldsymbol{\mu g} / \mathbf{~ k g}\end{array}$ & $\begin{array}{c}\text { Exceeding of the MPC (yes } \\
/ \mathbf{~ n o})\end{array}$ \\
\hline the carcass of broiler chickens & enrofloxacin & no \\
"Sample No. 1" & 3,72 & no \\
\hline the carcass of broiler chickens & enrofloxacin & no \\
"Sample No. 2" & 2,3 & \\
\hline the carcass of broiler chickens & enrofloxacin \\
"Sample No. 3" & 8,31 & \\
\hline
\end{tabular}

Thus, the concentration of the antibiotic enrofloxacin does not exceed the MPC. Thus, all three samples are usable not posing any threat to human health.

\section{Conclusions}

1. As a result of studying the range of food products of animal origin, it has been revealed that the amount of harmful substances (for example, antibiotics) meets the MPC standards, according to GOST R 55481-2013 GOST R 54904-2012, GOST R 52480-2005, GOST R ISO 17604, GOST R 51447, GOST 19496-2013, GOST 9225-81.

2. The study of Russian products from Moscow stores (such as meat, milk and poultry) for the possible presence of unacceptable components, has shown the following.

All milk samples of the trade marks "Sample No. 1", "Sample No. 2" and "Sample No. 3" meet the standard not exceeding the MPC value and are fit for consumption posing no threat to human health.

Samples of minced meat "No. 1", "No. 2" and "No. 3" are fit for consumption causing no harm to human health.

The samples of broiler chicken carcasses from various manufacturers "Sample No. 1", "Sample No. 2" and "Sample No. 3" are suitable for consumption inflicting no harm to human health. The concentration of detected antibiotics is below the MPC value. 
3. In all three samples, the antibiotic of the fluoroquinolone series, enrofloxacin, was found, the maximum permissible concentration of which was not exceeded.

Streptomycin was detected in two out of three test samples of milk, MPCs were not exceeded. In the studied samples of minced meat, the residual amount of the antibacterial substance was detected only in one sample "No. 3", however, the MPC of the substance sulfamethazine was not exceeded, which is not dangerous for humans.

\section{References}

1. N. G. Phillips, R. Ackley, E. R. Crosson et al., Environmental Pollution, 173, 1-4 (2013)

2. J. P. Kaye, I. C. Burke, A. R. Mosier, Ecological applications, 14(4), 975-981 (2004)

3. Y. Mayorova, V. Glebov, V. Erofeeva, S. Yablochnikov, B. Laver, Physiological Evaluation of the Cardiology System of Nonresident Students at Different Training Periods, E3S Web of Conferences 169, 5 (2020)

4. O. Maslennikova, V. Erofeeva, Biological contamination of soils in urbanized ecosystems by Toxocara sp. Eggs, E3S Web of Conferences 169, 6 (2020)

5. V. V. Erofeeva, O. V. Maslennikova, Hygiene and sanitation, 8, 897-902 (2019)

6. V. V. Erofeeva, V. V. Vasenev, Influence of Environmental Factors on the Development and Survival of Toxocara Sp. Eggs in Various Soil Substrates, Springer Geography, 52-57 (2020)

7. D. V. Ivanov, Izvestiya vysshikh uchebnykh zavedeniy, Geology and exploration, 4, 63-67 (2009)

8. G. A. Alexandrov, M. A. Sokolov, A. L. Stepanov, Soil science, 10, 1192-1194 (1996)

9. V. M. Semenov, I. K. Kravchenko, T. V. Kuznetsova, et. al., Microbiologiya. 73, 423429 (2004)

10. O. Yu. Goncharova, O. V. Semenyuk, G. V. Matyshak, A. A. Bobryk, Vestnik Mosk. un-ta, Soil Science, 17(2), 3-10 (2016)

11. Interaction of soil and atmospheric air, MSU Publishing House, 107 (1985) 